\title{
Echocardiographic assessment after surgical repair of tetralogy of Fallot
}

\author{
Mario Carminati *, Francesca R. Pluchinotta, Luciane Piazza, Angelo Micheletti, Diana Negura, \\ Massimo Chessa, Gianfranco Butera, Carmelo Arcidiacono, Antonio Saracino and Claudio Bussadori
}

Department of Pediatric Cardiology and Adult with Congenital Heart Disease, IRCCS San Donato Hospital, Milan, Italy

\section{Edited by:}

Oswin Grollmuss, Centre Chirurgical

Marie Lannelongue, France

Reviewed by:

Vladimiro Vida, University of Padua,

Italy

Cecile Tissot, Hôpitaux Universitaires de Genève, Switzerland

\section{*Correspondence:}

Mario Carminati, Department of

Pediatric Cardiology and Adult with

Congenital Heart Disease, IRCCS

Policlinico San Donato, Via Morandi

30, 20097 San Donato Milanese (MI),

Italy

e-mail:mario.carminati@

grupposandonato.it
Surgical correction of tetralogy of Fallot is still one of the most frequently performed intervention in pediatric cardiac surgery, and in many cases, it is far from being a complete and definitive correction. It is rather an excellent palliation that solves the problem of cyanosis, but predisposes the patients to medical and surgical complications during followup. The decision-making process regarding the treatment of late sequel is among the most discussed topics in adult congenital cardiology. In post-operative Fallot patients, echocardiography is used as the first method of diagnostic imaging and currently allows both a qualitative observation of the anatomical alterations and a detailed quantification of right ventricular volumes and function, of the right ventricular outflow tract, and of the pulmonary valve and pulmonary arteries. The literature introduced many quantitative echocardiographic criteria useful for the understanding of the pathophysiological mechanisms involving the right ventricle and those have made much more objective any decision-making processes.

Keywords: echocardiography, tetralogy of Fallot, right ventricular dysfunction, cardiac surgical procedures, strain rate

\section{INTRODUCTION}

The complete surgical correction of tetralogy of Fallot (ToF) was first introduced in 1955 (1), and it is now used all over the world. In recent years, the surgical technique has gone through various improvements and due to the complexity and variability of the phenotypic presentation of the disease it is now performed with different approaches tailored to the patient's anatomy, especially regarding the treatment of the right ventricular outflow tract obstruction and the related pulmonary valve stenosis. Initial ToF repair was mostly performed with transannular right ventricle (RV) outflow tract patch to relieve the obstruction. In most cases what we obtain after this surgical correction is far from a complete resolution of the disease. It is rather an excellent palliation that solves the problem of cyanosis, but predisposes the patients to subsequent interventions to treat the surgical sequelae. Nowadays, the most diffused surgical strategy is based on the presumption that the pulmonary annulus may be preserved and that a mixed lesion of moderate pulmonary stenosis and associated insufficiency is superior to the complete relief of obstruction and free pulmonary regurgitation.

In the long term, the residual pulmonary stenosis that remains after this conservative surgical approach and the free pulmonary regurgitation caused by the transannular patch graft used to enlarged the right ventricular outflow tract lead to the development of two pathophysiological conditions of the RV very different one from each other: RV hypertrophy and RV dilation.

Pulmonary valve regurgitation has been recognized as one of the most important risk factors for both right and left ventricular performance after the repair of ToF. Pulmonary regurgitation may be well tolerated for several years but, depending on its severity, it results in a progressive RV dilation and dysfunction.
Long-standing chronic RV volume overload causes dilation of the tricuspid annulus that results in some degrees of tricuspid regurgitation. RV dilation and tricuspid regurgitation are important risk factors for the development of arrhythmias and possibly sudden death (2). Over time RV changes and remodeling secondary to volume and pressure overload reduce left ventricular function. This is most likely to be due to the alteration in the left ventricular and septal geometry secondary to RV dilation, post-surgical paradoxical systolic septal motion, and ventricular dyssynchrony (3). Retention of some pulmonary stenosis in the RV outflow tract as it is done with a surgical conservative approach may limit the jet width of pulmonary regurgitation and provides a protective RV ventricular hypertrophy that diminishes the deleterious effects of the retrograde pulmonary flow. Rao and colleagues reported their experience with 31 patients who underwent complete repair of ToF with preservation of the pulmonary valve. The data from this study demonstrate that pulmonary valve preservation is possible in most patients ( 28 over 31 enrolled) and the RVOT obstruction present right after surgery regresses as the valve participates in somatic growth (4). However, pulmonary valve-preserving repair in patients with severe hypoplastic pulmonary valves remains challenging and controversial $(5,6)$. Deorsola and colleagues proposed the preliminary results of an innovative procedure consisting in the implant of an injectable biological pulmonary valve, designed for right infundibular surgery in adults; in babies: the valves, shrunken to a smaller diameter, enable the implantation of a device wider than otherwise possible in young patients and once in the pulmonary position tends to expand to its original size following patient's growth (7).

Imaging examination in adult post-operative patients with pulmonary regurgitation should be focused on the assessment of 
markers of RV function in order to identify the most appropriate timing for pulmonary valve replacement that remains controversial and is one of the most debated issues in the field (8). Several authors proposed cardiac magnetic resonance (CMRI) measurement of RV volumes as the most reliable indicators for pulmonary valve replacement: a RV end-diastolic volume $>170 \mathrm{ml} / \mathrm{m}^{2}$ or a $\mathrm{RV}$ end-systolic volume $>85 \mathrm{ml} / \mathrm{m}^{2}$ have been proposed (9) as a cut-off value for reoperation in order to obtain a substantial RV “normalization" after surgery. Other authors (10) considering the correlation between RV volumes, cardiac output, and exercise test changes after pulmonary valve replacement proposed a relatively more aggressive policy (RV end-diastolic volume $<150 \mathrm{ml} / \mathrm{m}$ ) (3) aiming to normalize the RV volumes, improve biventricular function, and submaximal exercise capacity after surgery (10).

\section{ECHOCARDIOGRAPHIC STUDY OF THE RIGHT VENTRICLE}

The echocardiographic study of the RV after ToF surgery should include dimensional and volumetric measurements to determine the degree of segmental and global RV dilatation.

Echocardiographic quantitative parameter used to evaluate the right ventricular function are distinguished in geometrical and non-geometrical parameters: the first are based on bidimensional and three-dimensional measurements of RV volumes, the second rely on various technologies including M-mode, myocardial Doppler imaging, tissue Doppler imaging (TDI), and 2D strain.

\section{GEOMETRICAL PARAMETERS}

Indication for bidimensional measures of the RV have been proposed in various guidelines (11) and original articles (12). Dimensions and function of RV outflow tract in Fallot patients can be assessed by $2 \mathrm{D}$ echocardiography by measuring the fractional shortening of the RV outflow tract (FS-RVOT $=[$ (end-diastolic length - end-systolic length)/end-diastolic length] $\times 100$ ); measures are taken form the short axis at the level of the aortic valve along a line from the center of the ultrasound beam to the center of the aortic valve (Figure 1) (13). Another index commonly used

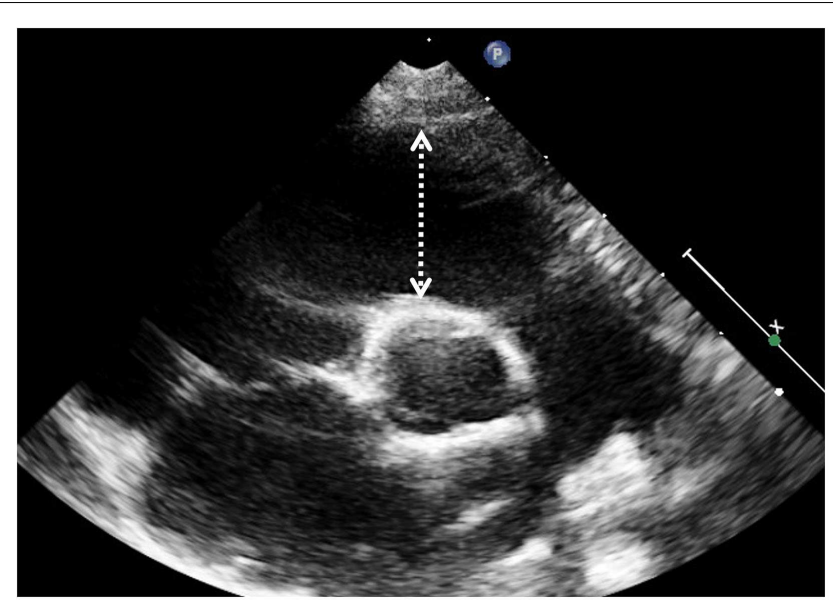

FIGURE 1 |The dotted arrow indicates the position where to measure the RVOT diameter. in clinical practice is the fractional area change. This simplified index represents a "surrogate" measurement of RV ejection fraction (EF) and is expressed as a percentage change of diastolic and systolic area of the RV inflow measured on an apical 4-chamber view optimized for the RV. This method is based on geometric assumptions valid for the conical shape left ventricle that may not apply to the RV in general and especially to the RV in patients after ToF repair where the outflow tract is often markedly dilated. In a recent study, FS-RVOT was measured together with fractional area change in order to asses regional and global RV systolic function in adults after repaired ToF and compared to EF measured by CMRI: in the study the authors find that the optimal cut-off values to detect significant systolic RV dysfunction (defined ad RV $\mathrm{EF}<35 \%$ on $\mathrm{CMRI}$ ) was a combination of fractional area change on 4 -chamber view $<30 \%$ and fractional shortening of the RV outflow tract $<25 \%$ (sensitivity $79 \%$, specificity $86 \%$ ) (13).

The complex RV anatomy could be better investigated using three-dimensional echocardiography (3DE). This technology allows better assessment of the pulmonary valve's morphology (14), and characterization of pulmonary flow (15) but underestimates RV volumes and EF $(16,17)$. Nonetheless, 3DE suffers by limitations such as low spatial and temporal resolution. A meta-analysis of 23 studies including a total of 807 patients (18) studied the accuracy of RV volumes and function determined by 3DE in comparison with CMRI and confirmed the tendency of 3DE to underestimate RV volumes and EF, especially when dealing with larger RV volumes ( $\mathrm{RV}$ end-diastolic volume $>200 \mathrm{ml}$ ) and younger patient (age <18 years) (19). Currently, 3DE RV assessment is probably not ready for routine clinical use in congenital heart disease patients with more than mild RV dilatation (19). Measurements of RV volumes are more reliable with CMRI that so far represents the gold standard for non-invasive quantitative assessment of the ventricular volumes (9). Cardiac MRI overcomes the echocardiographic limitation of poor image quality frequently encountered in patients who had several surgical procedures. However, the evaluation of the complex RV geometry requires a higher level of expertise and significant intra- and inter-operator variability for RV volume measurements on CMRI have been reported (20). Notwithstanding that, CMRI evaluation is recommended in all patients with repaired ToF and should be regularly used during clinical follow-up.

Cardiac MRI and echocardiography provide similar information useful for the optimal management of ToF patient. Echocardiography remains as the first-line diagnostic tool. Cardiac MRI is a valid alternative to echocardiography when ultrasound images do not have good resolution and when echocardiography measurements are borderline or ambiguous. Nowadays, echocardiography is superior in estimating gradients and pulmonary arterial pressure and offers optimal assessment of residual RV outflow tract obstruction and residual ventricular septal defect. Cardiac MRI is better than echocardiography for RV volumes and RV EF quantification, evaluation of the RV outflow tract obstruction and pulmonary artery conduits, and for pulmonary regurgitant flow estimation (21). Obstruction of the RV outflow tract observed in adult patients operated for ToF is more frequently caused by degeneration of the valved conduit surgically placed to correct pulmonary regurgitation. Optimal echocardiographic visualization 
of the site of obstruction is sometimes difficult to obtain because of the suboptimal windows due to previous sternotomy and conduit calcification. However, in patients who underwent percutaneous pulmonary valve implantation echocardiography almost always allows good visualization of the stent and of the prosthetic valve motion, and Doppler study of the blood flow through it. The most appropriate views to visualize the RV outflow tract and the pulmonary conduit are parasternal short axis and subcostal apical and short axis views. In addition, these views are ideal to study the integrity of the interventricular patch and to diagnose eventual residual interventricular shunts.

\section{NON-GEOMETRICAL INDEXES}

Echocardiographic indicators for studying velocity of displacement and deformation of the myocardium are aimed to a direct quantification of myocardial function not extrapolated from a change of shape and dimension.

Tricuspid annular plane systolic excursion (TAPSE) measures the systolic excursion of the RV annular plane toward the apex. It is a very easy echocardiographic measurement, rapid to measure in a busy clinical setting, and is widely used in clinical practice even if its reliability is still controversial $(22,23)$. In adults values of TAPSE lower than $18 \mathrm{~mm}$ are suggestive of RV longitudinal dysfunction while in children the absolute value of TAPSE must be indexed to RV longitudinal diameter (TAPSE/RV longitudinal diameter ratio lower than $25 \%$ suggests longitudinal dysfunction) $(24,25)$. TAPSE has some important limitations. First of all, in patients with severe RV hypertrophy radial contraction becomes the prevalent direction of RV systolic deformation (26) and TAPSE, measuring the longitudinal deformation, may underestimate the real systolic function (Figure 2). Then TAPSE is strongly preload dependent and this may reduce its sensitivity regarding systolic function. In fact, in case of severe RV volume overload (large atrial septal defect, severe tricuspid, or pulmonary regurgitation) TAPSE may show high values masking mild systolic dysfunction (Figure 3). Several studies showed that there is a weak or no correlation between TAPSE and RV EF in ToF patients (27).

Tissue Doppler imaging technique measures the velocities of cardiac tissue and has been studied for the assessment of RV function. Tissue Doppler compared to blood flow Doppler reflects directly myocardial function and is less subject to preload changes. However, TDI is still Doppler based, and therefore its major limitation remains the angle dependency (28). Because of this the RV TDI analysis can be only applied at the tricuspid annular level or to the basal segments.

Isovolumic acceleration time (IVA, Figure 4) is a TDI derived parameter that defines the myocardial acceleration during isovolumic contraction of tricuspid lateral annulus and has been proposed as a preload-independent indicator of RV contractility. It is calculated as the ratio of TDI derived peak myocardial velocity during isovolumetric contraction divided by the acceleration time. It has been validated in a variety of experimental and clinical settings. In a group of 124 patients after ToF repair IVA values measured at the tricuspid annulus and RV basal segments were lower in the affected population compared to normal controls and they correlated with the severity of pulmonary regurgitation (29). The two main limitations of using IVA derived values in the clinical setting are that IVA requires a good echocardiography equipment with high frame rate, and therefore has high variability among groups and centers, and that the physiological event to which IVA refers

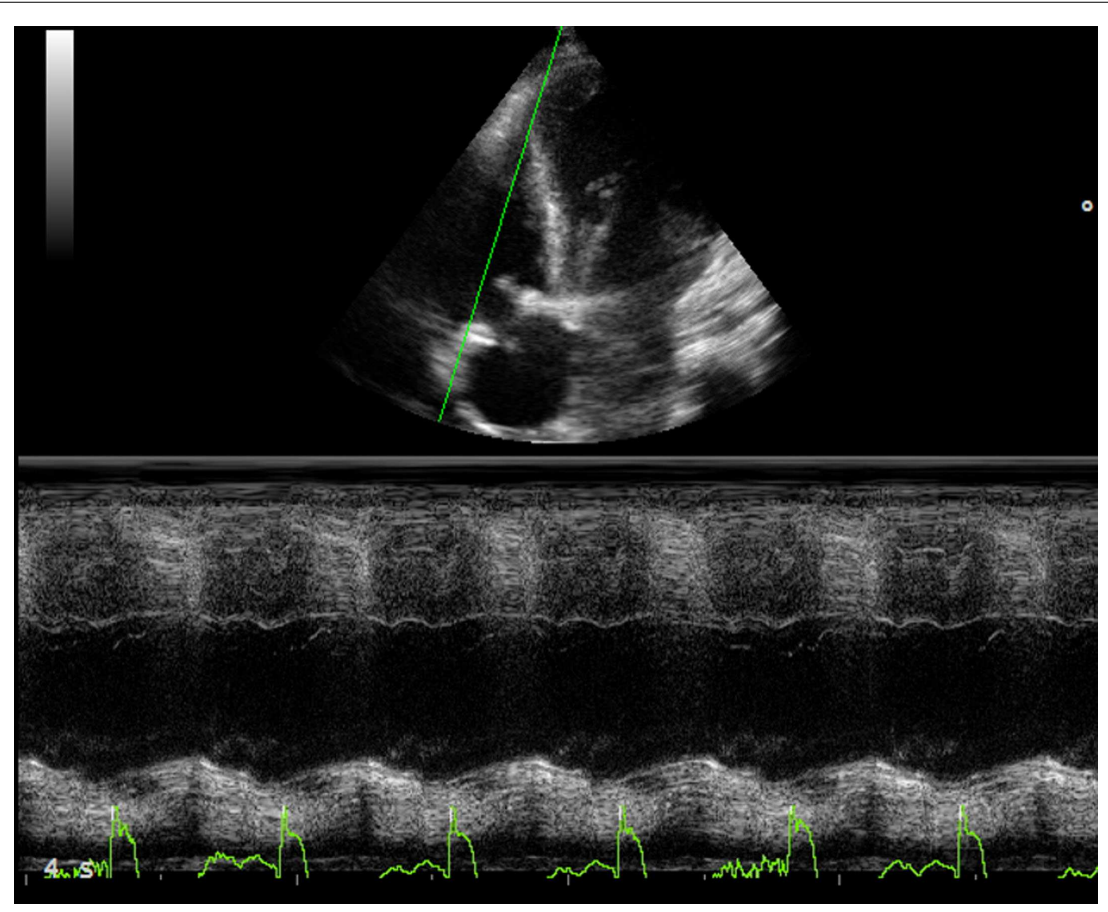

FIGURE 2 | Eighteen year-old man with a restrictive right ventricle, low value of TAPSE: $6 \mathbf{m m}$. 

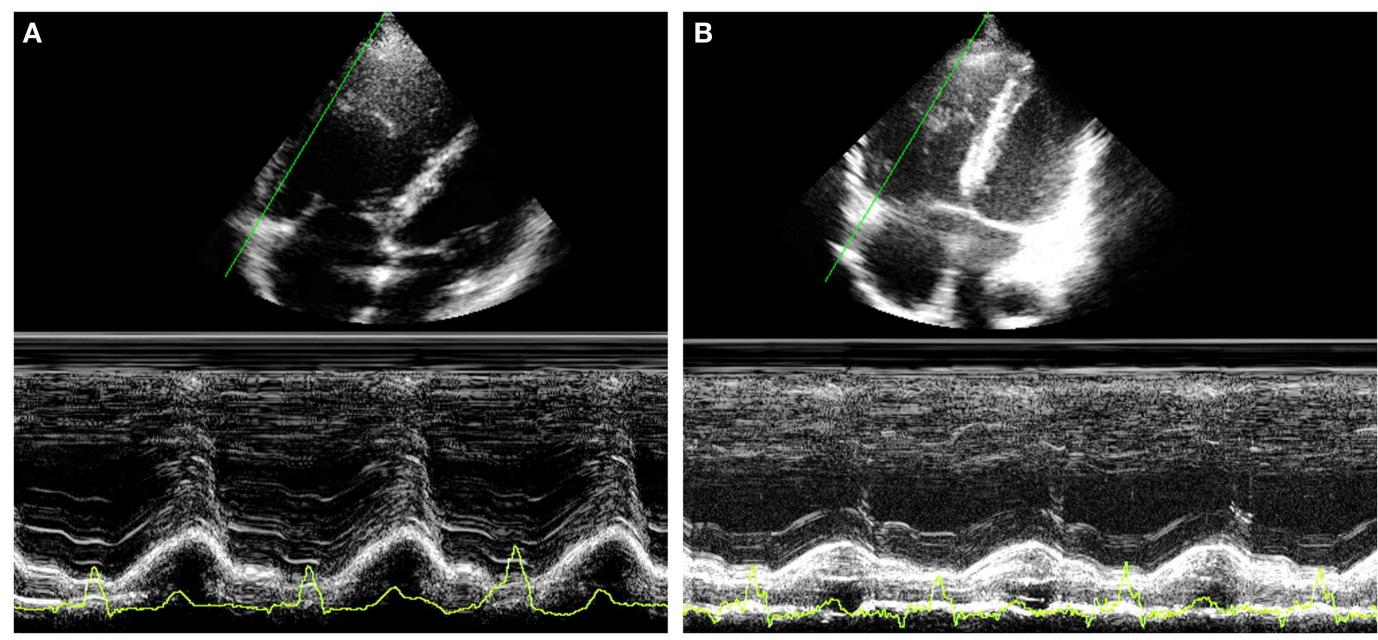

FIGURE 3 | Thirty year-old woman with severe pulmonary regurgitation. (A) High value of TAPSE (22 mm) due to the volume overload. (B) Normalization of TAPSE $24 \mathrm{~h}$ after percutaneous implantation of a pulmonary prosthetic valve.

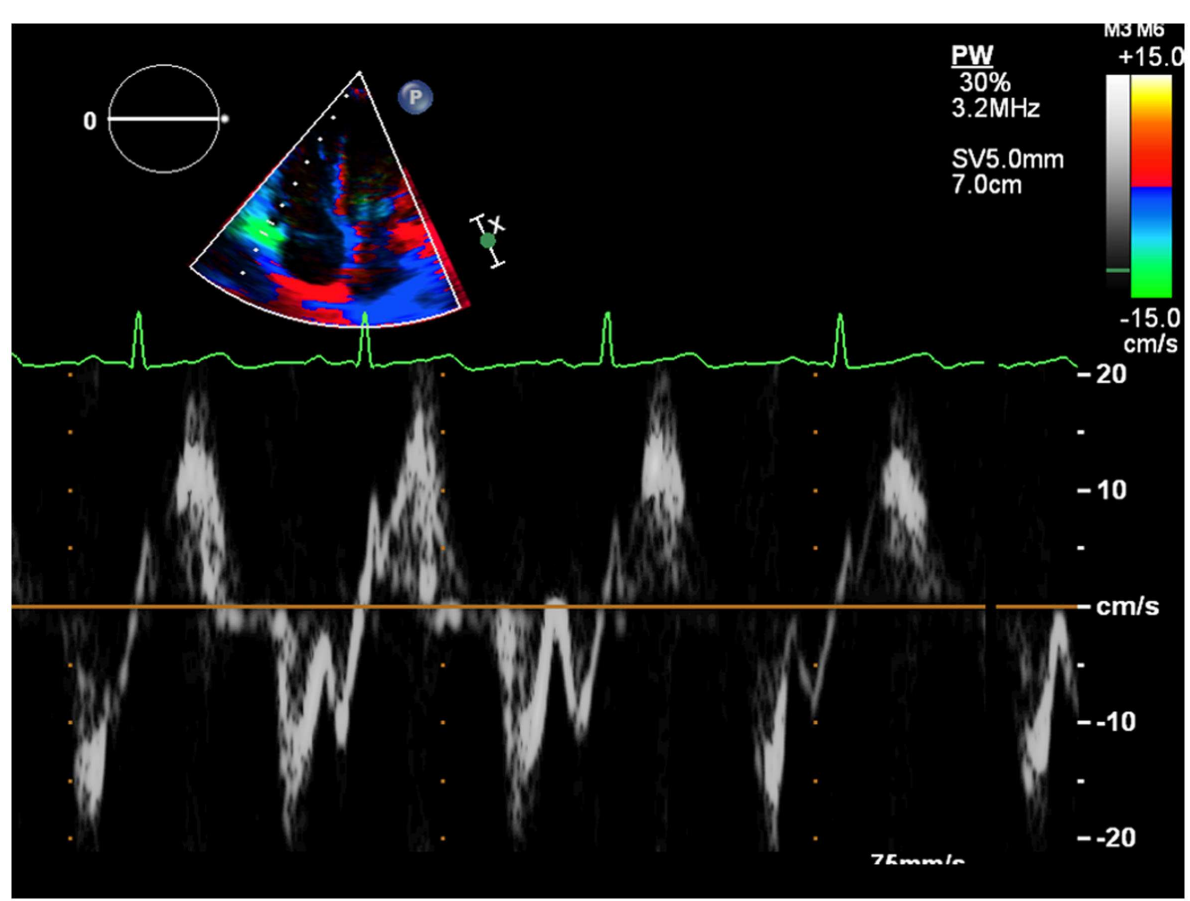

FIGURE 4 |The first rapid systolic wave represents the isovolumic contraction. The pendency of the curve estimates the isovolumic acceleration.

in the mechanics of the RV is not as well defined as it is in the left ventricle (30). Nevertheless, IVA (31), together with strain rate is the less load-dependent indexes available in echocardiography and it should be used for serial controls (32).

Strain and strain rate are largely used for direct quantification of systolic function. These newest 2D-based technologies overcome the limitation of Doppler angle dependence and are widely used to investigate left ventricular function. In many echocardiography laboratories, the experience on the strain and strain rate of the left ventricle is translated to evaluate RV function even if this use is considered "off label." Since none of the available 2D strain software includes a template for the study of RV, in our lab we use the template designed for the left ventricular apical 4-chamber view and arbitrarily divide the RV lateral wall into basal, mid, 


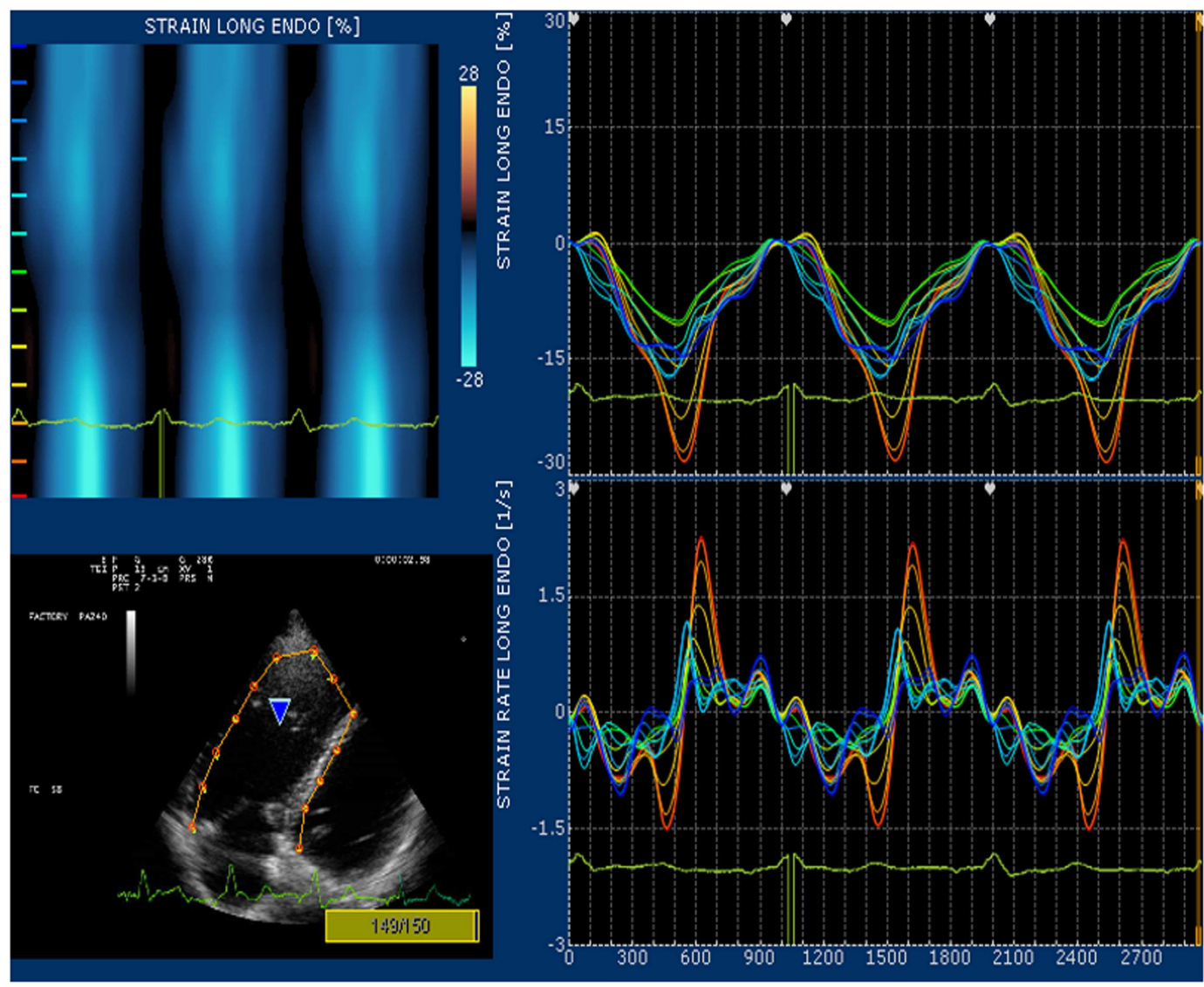

FIGURE 5 | High values of strain at the basal segment of lateral right ventricular wall.

and apical segments (32). Children and young adult operated for ToF present a various range of values for longitudinal strain and strain rate of right lateral wall and right interventricular septum. In case of severe pulmonary regurgitation with preserved RV systolic function, longitudinal strain is higher than normal at the basal lateral wall (Figure 5). On the other hand, patients with longstanding pulmonary regurgitation have decreased RV longitudinal strain that correlates with the degree of RV dilatation, severity of pulmonary regurgitation, and QRS duration (33). Depression of longitudinal strain is more evident in patient with dilated RV and stenosis of the pulmonary artery conduit. In this latter group of patients, a combination of pressure and volume overload causes stress on a previously dysfunctional RV with various degree of fibrosis and induces an evident afterload mismatch with very low values of longitudinal strain and strain rate. Low longitudinal strain is found also in severely hypertrophic restrictive RV, because the hypertrophy involves mainly the circumferential fibers and the systolic function of the RV is switched from a most prevalent longitudinal to radial deformation. In this case, a more correct quantification of RV systolic function can be done by measuring RV transversal strain (Figure 6). In patients after correction of ToF, global and RV free wall longitudinal systolic strain has been shown to continue to deteriorate despite unchanged RV EF, suggesting that regional wall motion assessment may detect early
RV dysfunction (34). In patients with stenosis of the pulmonary conduit treated with percutaneous implant of a biological pulmonary valve, longitudinal strain of the RV increases significantly after pulmonary valve replacement but it never reaches normal values $(35,36)$.

\section{DOPPLER STUDY}

Echocardiographic Doppler study in ToF as in many other cardiac diseases allows to obtain non-invasively hemodynamic information useful for decision making. Measure of pulmonary gradient with continuous wave Doppler allows to estimate the severity of pulmonic stenosis but could be sometimes not reliable in case of an anomalous anatomy (tunnel stenosis), a suboptimal alignment of the ultrasound beam with pulmonary flow, or in case of pulmonary hypertension and in pulmonary branch stenosis. Pulmonary hypertension and peripheral pulmonary stenosis lead to an underestimation of the severity of the stenosis (reduction of the anterograde peak gradient), and worsens pulmonary regurgitation. Underestimation of pulmonary stenosis should be suspected when the velocity of the tricuspid regurgitation exceeds consistently the velocity of the pulmonary flow. The suspect of pulmonary branch stenosis, which is more common than pulmonary hypertension in operated ToF patients, needs to be ruled out at the time of pulmonary valve replacement. 


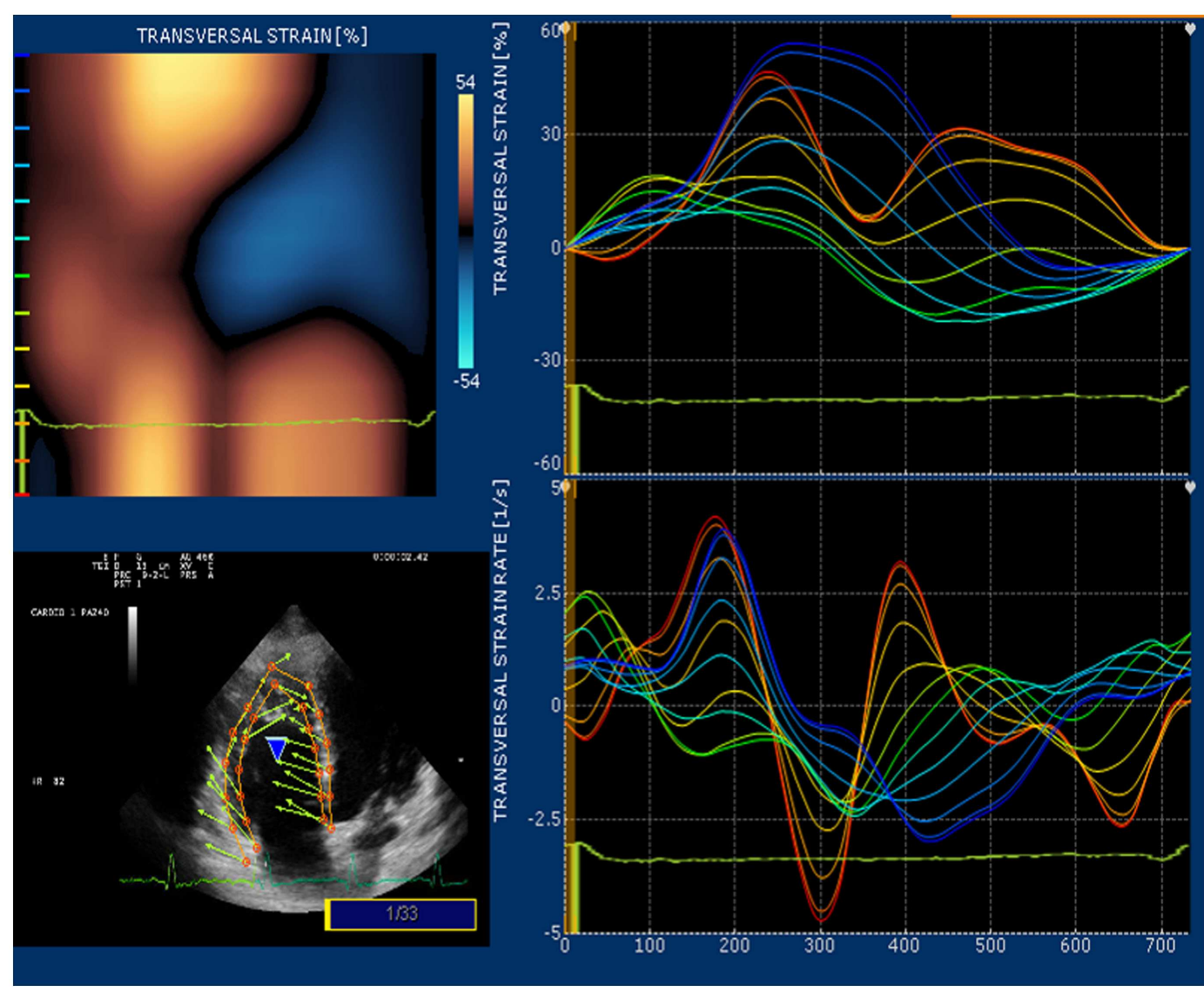

FIGURE 6 | High values of transversal strain in a ToF operated patient with restrictive RV

First assessment of pulmonary regurgitation severity should be done with color Doppler: a severe pulmonary regurgitation is recognizable on color Doppler flow as a large retrograde flow that persists beyond the first half of diastole invading the RV outflow tract. After relieve of RV outflow tract obstruction with a transannular patch a severe pulmonary insufficiency appears as a "free floating" bidirectional flow across the pulmonary annulus. To record appropriately the color flow, it is recommended to set the color scale at the maximal pulse repetition frequency available in order to avoid turbulence overestimation. In severe pulmonary regurgitation, the most important determinants of the regurgitant volume are the compliance of the RV and the pulmonary artery, the size of the pulmonary branches, the pulmonary vascular resistance, and its changes throughout the cardiac cycle (37). Quantification of pulmonary regurgitation severity is assessed more precisely using spectral Doppler. The regurgitant velocity profile expresses the pressure gradient between the main pulmonary artery and the $\mathrm{RV}$ during diastole. If pulmonary diastolic pressures are normal, peak velocity is not higher than $1 / \mathrm{ms}$. An indicator of severity is the precocity of the equalization of the two pressures; for example, in case of mild pulmonary regurgitation the regurgitant flow occupies the whole diastole while in patients operated for $\mathrm{ToF}$ the high regurgitant volume combined with a reduced compliant RV determinates an early interruption of the regurgitation (Figure 7).
A quantitative assessment of pulmonary regurgitation severity is based on the deceleration velocity of the regurgitant flow known as pressure half time (PHT), the time in milliseconds taken to reach half of the pressure gradient. PHT could be easily measured using continuous wave Doppler. In a clinical validation study, PHT was demonstrated to be inversely correlated to the pulmonary regurgitant fraction measured by CMRI, and values of PHT under $100 / \mathrm{ms}$ were a highly specific and significant index of severe pulmonary regurgitation (38).

\section{RESTRICTIVE RIGHT VENTRICLE}

Right ventricle restrictive physiology is a condition observed in congenital heart diseases in which the RV systolic pressure is chronically elevated, and it is mostly encountered in adult patient operated of ToF. A restrictive physiology is typically seen in severely hypertrophied and fibrotic RV with normal sized or only mild ventricular dilatation due to the increasing myocardial stiffness. However, restrictive physiology could also be observed in severely dilated RV. In this case, the restrictive physiology should be intended as a manifestation of poor ventricular compliance that may occur at any stage of the RV remodeling after ToF surgery. Spectral Doppler may be used to identify this condition. Restrictive physiology may limit the degree of pulmonary regurgitation because of an increased mid-to-late diastolic pressure that 


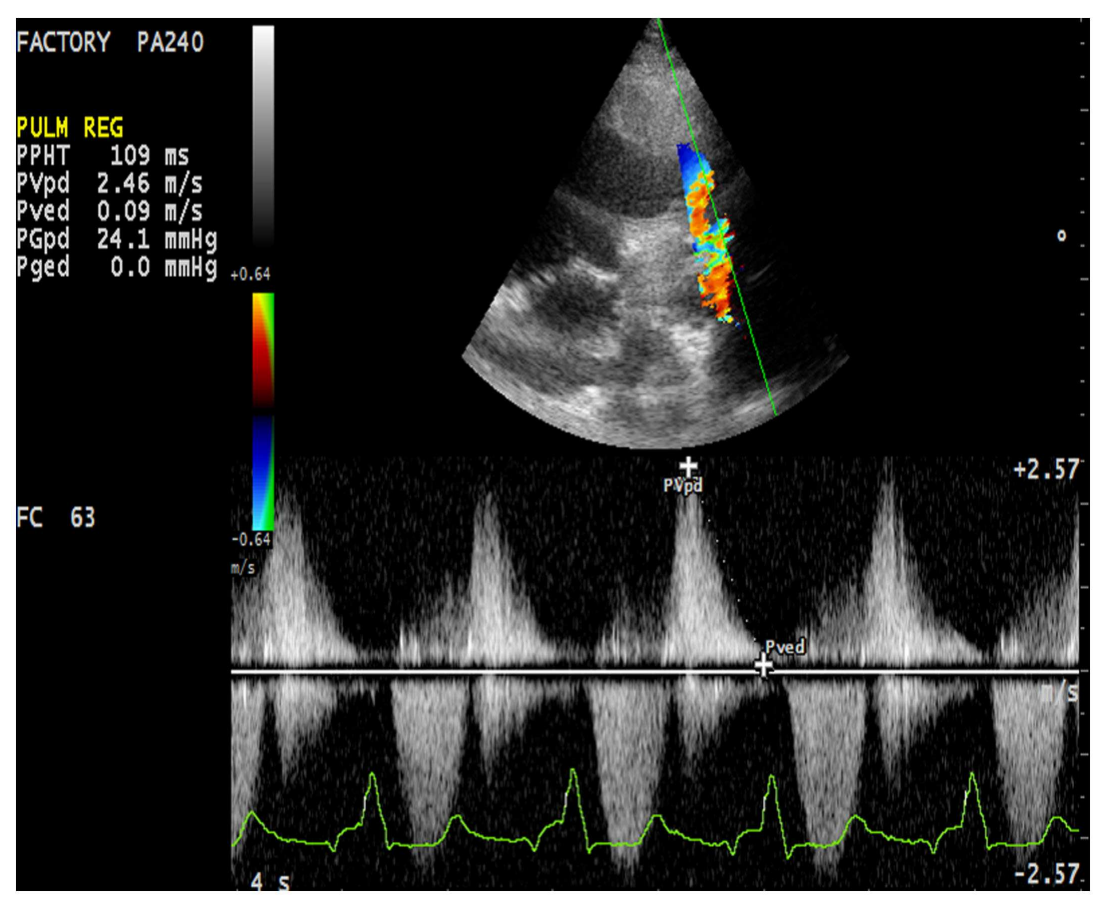

FIGURE 7 | Severe pulmonary insufficiency with early end and low values of pulmonary pressure half time (PHT).

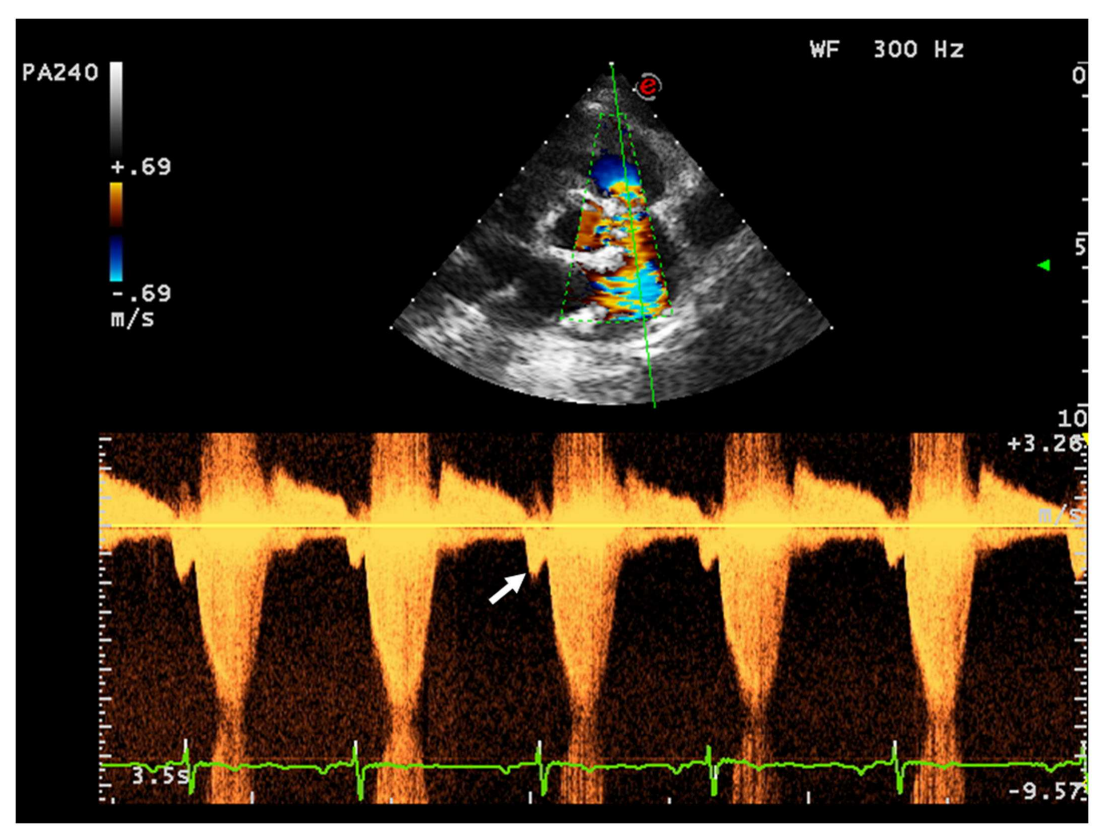

FIGURE 8 |The arrow indicates the end-diastolic forward flow

overrides the pulmonary artery pressure. Therefore, the Doppler curve of the pulmonary regurgitation shows an early peak and an early end regurgitation. This gradient is defined the end-diastolic forward flow (EDFF) and appears just after the atrial contraction
Figure 8. EDFF can be identified even in normal people during inspiration and for this reason, to define a RV restriction, the late diastolic anterograde flow should be recorded throughout the entire respiratory cycle: if respiration is not monitored during the 
exam the identification of EDFF in at least three consecutive cardiac cycles is considered pathognomonic of RV restriction. The limitation of the degree of pulmonary regurgitation in patients with restrictive RV has a protective effect on the RV by reducing the effect of volume overload (39). Severity of preoperative pulmonary stenosis and older age at time of intervention influence the post-operative RV hypertrophy and fibrosis and they represent the most important predisposing factors to a restrictive physiology of the RV (40). Patients with restrictive RV have a better performance at exercise test compared to other patients operated for ToF that have severe PR and do not have this diastolic dysfunction (41).

\section{CONCLUSION}

Echocardiography is the exam most frequently performed in the follow-up of patients after complete ToF surgical correction. Use of validated echocardiographic indexes based either on conventional echocardiography and newest technologies such as $3 \mathrm{DE}$ and $2 \mathrm{D}$ strain allows us to integrate the usual subjective observational information with a new set of parameters useful to quantify RV function.

However, quantitative criteria represent an advantage when they are objectively repeatable, clinically reliable, and comparable with other quantitative values. This is not yet completely true for some of these echocardiographic indices applied to the RV, but in the near future it is reasonable to expect powerful clinical validation studies and improvements of the technologies in use.

Echocardiography with the development of new technologies such as 3DE, 2D strain, and myocardial Doppler imaging has made a great contribution to the follow-up of complex patients affected by congenital heart disease. Notwithstanding that, at present CMRI represents the gold standard for non-invasive quantitative assessment of the RV and should be regularly used in repaired ToF patients especially to evaluate those parameters in which CMRI is considered superior to echocardiography, such as $\mathrm{RV}$ volumes and RV EF.

The decisions about the complex diagnostic and therapeutic plans have to go through the analysis of all diagnostic techniques applied in these patients, as echocardiography, cardiopulmonary exercise tests, CMRI, CT, hemodynamic studies, electrophysiology, and biochemistry studies.

Furthermore, the introduction of more quantitative echocardiographic parameters for the evaluation of the RV has not decreased the number of cardiac catheterizations but it has indeed improved the added value of these invasive procedures probably making more accurate the indications to perform them.

The synergy between the information obtained by various methodologies in which the refinement of one technique also improves the level of information obtainable from the others is a further confirmation of the fact that the best diagnostic and therapeutic strategy can be identified only on the base of a multiparametric analysis that correlates data obtained from clinical and instrumental examinations.

\section{REFERENCES}

1. Lillehei C, Walton CM, Warden Herbert E, Read Raymond C, Aust Joseph B, DeWall Richard A, et al. Direct vision intracardiac surgical correction of the tetralogy of Fallot, pentalogy of Fallot and pulmonary atresia defects. Ann Surg (1955) 142:418-45. doi:10.1097/00000658-195509000-00010
2. Gatzoulis MA, Balaji S, Webber SA, Siu SC, Hokanson JS, Poile C, et al. Risk factors for arrhythmia and sudden cardiac death late after repair of tetralogy of Fallot: a multicentre study. Lancet (2000) 356:975-81. doi:10.1016/S01406736(00)02714-8

3. Liang XC, Cheung EW, Wong SJ, Cheung YF. Impact of right ventricular volume overload on three-dimensional global left ventricular mechanical dyssynchrony after surgical repair of tetralogy of Fallot. Am J Cardiol (2008) 102:1731-6. doi:10.1016/j.amjcard.2008.07.062

4. Rao V, Kadletz M, Hornberger LK, Freedom RM, Black MD. Preservation of the pulmonary valve complex in tetralogy of Fallot: how small is too small? Ann Thorac Surg (2000) 69:176-9. doi:10.1016/S0003-4975(99)01152-2

5. Bacha E. Valve-sparing options in tetralogy of Fallot surgery. Semin Thorac Cardiovasc Surg Pediatr Card Surg Annu (2012) 15:24-6. doi:10.1053/j.pcsu.2012. 01.006

6. Ito H, Ota N, Murata M, Tosaka Y, Ide Y, Tachi M, et al. Technical modification enabling pulmonary valve-sparing repair of a severely hypoplastic pulmonary annulus in patients with tetralogy of Fallot. Interact Cardiovasc Thorac Surg (2013) 16:802-7. doi:10.1093/icvts/ivt095

7. Deorsola L, Abbruzzese PA. Use of oversized injectable valves in growing children for total repair of right ventricular outflow tract anomalies (preliminary results). Tex Heart Inst J (2014) 41:373-80. doi:10.14503/THIJ-13-3359

8. Piazza L, Chessa M, Giamberti A, Bussadori CM, Butera G, Negura DG, et al. Timing of pulmonary valve replacement after tetralogy of Fallot repair. Expert Rev Cardiovasc Ther (2012) 10:917-23. doi:10.1586/erc.12.67

9. Therrien J, Provost Y, Merchant N, Williams W, Colman J, Webb G. Optimal timing for pulmonary valve replacement in adults after tetralogy of Fallot repair. Am J Cardiol (2005) 95:779-82. doi:10.1016/j.amjcard.2004.11.037

10. Frigiola A, Tsang V, Bull C, Coats L, Khambadkone S, Derrick G, et al. Biventricular response after pulmonary valve replacement for right ventricular outflow tract dysfunction: is age a predictor of outcome? Circulation (2008) 118:S182-90. doi:10.1161/CIRCULATIONAHA.107.756825

11. Lang RM, Bierig M, Devereux RB, Flachskampf FA, Foster E, Pellikka PA, et al. Recommendations for chamber quantification: a report from the American Society of Echocardiography's Guidelines and Standards Committee and the Chamber Quantification Writing Group, developed in conjunction with the European Association of Echocardiography, a branch of the European Society of Cardiology. J Am Soc Echocardiogr (2005) 18(12):1440-63.

12. Denslow S, Wiles HB. Right ventricular volumes revisited: a simple model and simple formula for echocardiographic determination. J Am Soc Echocardiogr (1998) 11:864-73. doi:10.1016/S0894-7317(98)70006-9

13. Greutmann M, Tobler D, Biaggi P, Mah ML, Crean A, Wald RM, et al. Echocardiography for assessment of regional and global right ventricular systolic function in adults with repaired tetralogy of Fallot. Int J Cardiol (2012) 157(1):53-8. doi:10.1016/j.ijcard.2010.11.017

14. Kelly NF, Platts DG, Burstow DJ. Feasibility of pulmonary valve imaging using three-dimensional transthoracic echocardiography. J Am Soc Echocardiogr (2010) 23:1076-80. doi:10.1016/j.echo.2010.06.015

15. Irvine T, Li XN, Rusk R, Lennon D, Sahn DJ, Kenny A. Three dimensional colour Doppler echocardiography for the characterisation and quantification of cardiac flow events. Heart (2000) 84(Suppl 2):II2-6. doi:10.1136/heart.84. suppl_2.ii2

16. Iriart X, Montaudon M, Lafitte S, Chabaneix J, Reant P, Balbach T, et al. Right ventricle three-dimensional echography in corrected tetralogy of Fallot: accuracy and variability. Eur J Echocardiogr (2009) 10(6):784-92. doi:10.1093/ ejechocard/jep071

17. Khoo NS, Young A, Occleshaw C, Cowan B, Zeng IS, Gentles TL. Assessments of right ventricular volume and function using three-dimensional echocardiography in older children and adults with congenital heart disease: comparison with cardiac magnetic resonance imaging. JAm Soc Echocardiogr (2009) 22:1279-88. doi:10.1016/j.echo.2009.08.011

18. Shimada YJ, Shiota M, Siegel RJ, Shiota T. Accuracy of right ventricular volumes and function determined by three-dimensional echocardiography in comparison with magnetic resonance imaging: a meta-analysis study. J Am Soc Echocar$\operatorname{diogr}$ (2010) 23:943-53. doi:10.1016/j.echo.2010.06.029

19. Crean AM, Maredia N, Ballard G, Menezes R, Wharton G, Forster J, et al. $3 \mathrm{D}$ echo systematically underestimates right ventricular volumes compared to cardiovascular magnetic resonance in adult congenital heart disease patients with moderate or severe RV dilatation. J Cardiovasc Magn Reson (2011) 13:78. doi:10.1186/1532-429X-13-78 
20. Schwerzmann M, Samman AM, Salehian O, Holm J, Provost Y, Webb GD, et al. Comparison of echocardiographic and cardiac magnetic resonance imaging for assessing right ventricular function in adults with repaired tetralogy of Fallot. Am J Cardiol (2007) 99:1593-7. doi:10.1016/j.amjcard.2007.01.035

21. Kilner PJ, Geva T, Kaemmerer H, Trindade PT, Schwitter J, Webb GD. Recommendations for cardiovascular magnetic resonance in adults with congenital heart disease from the respective working groups of the European society of cardiology. Eur Heart J (2010) 31:794-805. doi:10.1093/eurheartj/ ehp586

22. Kjaergaard J, Iversen KK, Akkan D, Moller JE, Kober LV, Torp-Pedersen C, et al. Predictors of right ventricular function as measured by tricuspid annular plane systolic excursion in heart failure. Cardiovasc Ultrasound (2009) 7:51. doi:10.1186/1476-7120-7-51

23. Lopez-Candales A, Rajagopalan N, Saxena N, Gulyasy B, Edelman K, Bazaz R. Right ventricular systolic function is not the sole determinant of tricuspid annular motion. Am J Cardiol (2006) 98:973-7. doi:10.1016/j.amjcard.2006.04. 041

24. Koestenberger M, Ravekes W, Everett AD, Stueger HP, Heinzl B, Gamillscheg A, et al. Right ventricular function in infants, children and adolescents: reference values of the tricuspid annular plane systolic excursion (TAPSE) in 640 healthy patients and calculation of z score values. J Am Soc Echocardiogr (2009) 22:715-9. doi:10.1016/j.echo.2009.03.026

25. Nunez-Gil IJ, Rubio MD, Carton AJ, Lopez-Romero P, Deiros L, Garcia-Guereta $\mathrm{L}$, et al. Determination of normalized values of the tricuspid annular plane systolic excursion (TAPSE) in 405 Spanish children and adolescents. Rev Esp Cardiol (2011) 64:674-80. doi:10.1016/j.recesp.2011.04.006

26. Di Salvo G, Pacileo G, Rea A, Limongelli G, Baldini L, D’Andrea A, et al. Transverse strain predicts exercise capacity in systemic right ventricle patients. Int J Cardiol (2010) 145:193-6. doi:10.1016/j.ijcard.2009.05.028

27. Koestenberger M, Nagel B, Ravekes W, Everett AD, Stueger HP, Heinzl B, et al. Tricuspid annular plane systolic excursion and right ventricular ejection fraction in pediatric and adolescent patients with tetralogy of Fallot, patients with atrial septal defect, and age-matched normal subjects. Clin Res Cardiol (2011) 100:67-75. doi:10.1007/s00392-010-0213-z

28. Bussadori C, Moreo A, Di Donato M, De Chiara B, Negura D, Dall'Aglio E, et al. A new 2d-based method for myocardial velocity strain and strain rate quantification in a normal adult and paediatric population: assessment of reference values. Cardiovasc Ultrasound (2009) 7:8. doi:10.1186/1476-7120-7-8

29. Frigiola A, Redington AN, Cullen S, Vogel M. Pulmonary regurgitation is an important determinant of right ventricular contractile dysfunction in patients with surgically repaired tetralogy of Fallot. Circulation (2004) 110:II153-7. doi:10.1161/01.CIR.0000138397.60956.c2

30. Redington AN, Van Arsdell GS, Anderson RH. Congenital Diseases in the Right Heart. London: Springer (2009).

31. Vogel M, Schmidt MR, Kristiansen SB, Cheung M, White PA, Sorensen K, et al. Validation of myocardial acceleration during isovolumic contraction as a novel noninvasive index of right ventricular contractility: comparison with ventricular pressure-volume relations in an animal model. Circulation (2002) 105:1693-9. doi:10.1161/01.CIR.0000013773.67850.BA

32. Bussadori C, Salvo GD, Pluchinotta FR, Piazza L, Gaio G, Russo MG, et al. Evaluation of right ventricular function in adults with congenital heart defects. Echocardiography (2014) 32(Suppl 1):38-52. doi:10.1111/echo.12566

33. Weidemann F, Eyskens B, Mertens L, Dommke C, Kowalski M, Simmons L, et al. Quantification of regional right and left ventricular function by ultrasonic strain rate and strain indexes after surgical repair of tetralogy of Fallot. Am J Cardiol (2002) 90:133-8. doi:10.1016/S0002-9149(02)02435-9

34. Scherptong RW, Mollema SA, Blom NA, Kroft LJ, de Roos A, Vliegen HW, et al. Right ventricular peak systolic longitudinal strain is a sensitive marker for right ventricular deterioration in adult patients with tetralogy of Fallot. Int J Cardiovasc Imaging (2009) 25:669-76. doi:10.1007/s10554-009-9477-7

35. Kutty S, Deatsman SL, Russell D, Nugent ML, Simpson PM, Frommelt PC. Pulmonary valve replacement improves but does not normalize right ventricular mechanics in repaired congenital heart disease: a comparative assessment using velocity vector imaging. J Am Soc Echocardiogr (2008) 21:1216-21. doi:10.1016/j.echo.2008.08.009

36. Moiduddin N, Asoh K, Slorach C, Benson LN, Friedberg MK. Effect of transcatheter pulmonary valve implantation on short-term right ventricular function as determined by two-dimensional speckle tracking strain and strain rate imaging. Am J Cardiol (2009) 104:862-7. doi:10.1016/j.amjcard.2009. 05.018

37. Presson RGJ, Baumgartner WA Jr, Peterson AJ, Glenny RW, Wagner WW Jr. Pulmonary capillaries are recruited during pulsatile flow. J Appl Physiol (2002) 92(3):1183-90. doi:10.1152/japplphysiol.00845.2001

38. Silversides CK, Veldtman GR, Crossin J, Merchant N, Webb GD, McCrindle BW, et al. Pressure half-time predicts hemodynamically significant pulmonary regurgitation in adult patients with repaired tetralogy of Fallot. J Am Soc Echocardiogr (2003) 16:1057-62. doi:10.1016/S0894-7317(03)00553-4

39. Gatzoulis MA, Elliott JT, Guru V, Siu SC, Warsi MA, Webb GD, et al. Right and left ventricular systolic function late after repair of tetralogy of Fallot. Am J Cardiol (2000) 86:1352-7. doi:10.1016/S0002-9149(00)01241-8

40. Munkhammar P, Cullen S, Jogi P, de Leval M, Elliott M, Norgard G. Early age at repair prevents restrictive right ventricular (RV) physiology after surgery for tetralogy of Fallot (TOF): diastolic RV function after TOF repair in infancy. J Am Coll Cardiol (1998) 32:1083-7. doi:10.1016/S0735-1097(98)00351-9

41. Gatzoulis MA, Clark AL, Cullen S, Newman CG, Redington AN. Right ventricular diastolic function 15 to 35 years after repair of tetralogy of Fallot. Restrictive physiology predicts superior exercise performance. Circulation (1995) 91:1775-81. doi:10.1161/01.CIR.91.6.1775

Conflict of Interest Statement: The authors declare that the research was conducted in the absence of any commercial or financial relationships that could be construed as a potential conflict of interest.

Received: 21 October 2014; accepted: 14 January 2015; published online: 02 February 2015 .

Citation: Carminati M, Pluchinotta FR, Piazza L, Micheletti A, Negura D, Chessa M, Butera G, Arcidiacono C, Saracino A and Bussadori C (2015) Echocardiographic assessment after surgical repair of tetralogy of Fallot. Front. Pediatr. 3:3. doi: 10.3389/fped.2015.00003

This article was submitted to Pediatric Cardiology, a section of the journal Frontiers in Pediatrics.

Copyright (C) 2015 Carminati, Pluchinotta, Piazza, Micheletti, Negura, Chessa, Butera, Arcidiacono, Saracino and Bussadori. This is an open-access article distributed under the terms of the Creative Commons Attribution License (CC BY). The use, distribution or reproduction in other forums is permitted, provided the original author (s) or licensor are credited and that the original publication in this journal is cited, in accordance with accepted academic practice. No use, distribution or reproduction is permitted which does not comply with these terms. 